\title{
Obituaries
}

Obituaries should be submitted by email to Kate Maynard at k.maynard@nature.com.

All submitted obituaries should be 400 words maximum in length (apart from obituaries for past presidents of the BDA

where the length should be $700-800$ words)

Content of the obituary is down to the individual author, and the approval of the family should be given for the obituary prior

to submission to the $B D J$.

\section{JOHN LOWRY CBE}

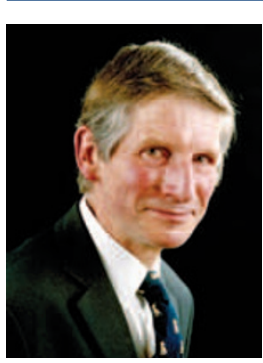

John Lowry graduated from the University of Manchester in dentistry in 1963 and in medicine in 1970. He was appointed consultant oral and maxillofacial surgeon in Bolton in 1976 and developed an outstanding clinical service linked with Burnley, Bury and Blackburn.

He was committed to postgraduate education and was appointed Visiting Professor of Surgery in the University of Central Lancashire. He was Honorary Civilian Consultant in Postgraduate Dental Education to the Army. Elected to the Board of the Faculty of Dental Surgery of the Royal College of Surgeons of England he played a leading role in the evolution of examinations in dentistry. He was elected Dean in 2001 and subsequently awarded the Colyer Gold Medal of the Faculty and elected a Fellow of the College.

He was President of the British Association of Oral and Maxillofacial Surgeons in 2001 and was a recipient of the Down Surgical Prize. He had been Secretary-General to the European Association for CranioMaxillofacial for the last ten years.

Within the BDA he was President of the Hospitals Group and served as Chairman of the Central Committee of Hospital Dental Services. He proved an effective leader and ambassador of his profession. He commanded respect but always had an inclusive approach. He was awarded the John Tomes Medal in 2005.

John was appointed Chairman of the Standing Dental Advisory Committee in 2000 and was invited to chair working parties to develop policy in a number of key areas within dentistry. He chaired the Standing Joint Advisory Committee on Anaesthesia for Dentistry and other groups to agree standards in anaesthesia and sedation. From an early stage he led the development of clinical guidelines, including seminal work on the management of third molars. His wide contributions were recognised by Fellowships of the Royal College of Anaesthetists, the Faculty of General Dental Practice (UK), and the Faculty of Dental Surgery of the Royal College of Surgeons of Edinburgh. He was appointed CBE in 2003.

John Lowry worked tirelessly for his profession and the interests of patients. He died on 29 September 2008 aged 66 after a short illness. He is survived by his wife Valerie, daughter Michelle and son Johnny, and grandsons Lawson and Louis. We extend our deepest sympathy.

David Barnard \&t Warren Jones

\section{ROBERT NAIRN}

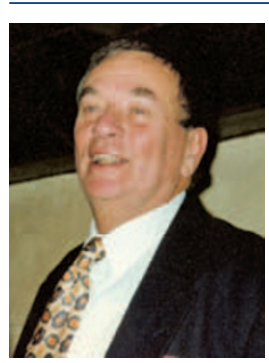

Robert (Bob) Nairn died of a fatal stroke at the age of 78 . Although restricted in mobility in the last few years he maintained an active and enthusiastic zest for life to his last day.

Born in Adelaide he excelled academically and qualified as a dentist in 1952. Almost immediately he set sail and arrived in the UK to the celebrations for the Queen's coronation in 1953. He furthered his career at the Eastman Dental Hospital where he studied oral surgery and followed this with a Masters degree in prosthetics at Ohio State University under the great Carl Boucher. On his return he worked at Guy's Hospital Dental School with Derek Neill before taking up an appointment at the Royal Dental Hospital where he became head of the prosthetics department. Following the Royal's amalgamation and move to Guy's in 1985, he instigated and ran a successful Masters programme there in prosthetics.

His collaboration with Derek Neill produced the definitive work Complete denture prosthetics used by generations of dental students. For many years he edited the Journal of Dentistry and was an international authority on kinesiography, jaw relationships, occlusion and removable prosthodontics, especially complete dentures. He was an active member and a former president of the BSSPD, a founder member of the European Prosthodontic Association and a member of the American Dental Society of London. He was an exacting and thorough clinician with high expectations of his staff and students, balanced with an extremely entertaining personality, some may say outrageous, often involving himself in the more esoteric delights of student life at the RDH. There is no doubt that his teaching of removable prosthodontics has improved the quality of life for many people and is his lasting legacy.

Continually in search of the perfect cottage Bob retired to the New Forest in 1995 and from there continued his second great passion of sailing. He was a true polymath with a deep understanding of music, politics, philosophy and the arts, writing a blog and often having letters published in the newspapers. He cared dearly and whilst not tolerating fools and the earnest he was very generous to his wide circle of friends. He leaves behind his partner of nearly 30 years and a gap in the lives of many.

C. Allen 